\title{
Particulate matter and risk of parkinson disease in a large prospective study of women
}

\author{
Natalia Palacios ${ }^{1,2^{*}}$, Kathryn C Fitzgerald ${ }^{1,3}$, Jaime E Hart ${ }^{2,4}$, Marc G Weisskopf ${ }^{4,5}$, Michael A Schwarzschild ${ }^{3}$, \\ Alberto Ascherio ${ }^{1,2,5}$ and Francine Laden ${ }^{2,4,5}$
}

\begin{abstract}
Background: Exposure to air pollution has been implicated in a number of adverse health outcomes and the effect of particulate matter (PM) on the brain is beginning to be recognized. Yet, no prospective study has examined the association between PM and risk of Parkinson Disease. Thus, our goal was assess if exposure to particulate matter air pollution is related to risk of Parkinson's disease (PD) in the Nurses' Health Study (NHS), a large prospective cohort of women.
\end{abstract}

Methods: Cumulative average exposure to different size fractions of PM up to 2 years before the onset of PD, was estimated using a spatio-temporal model by linking each individual's places of residence throughout the study with location-specific air pollution levels. We prospectively followed 115,767 women in the NHS, identified 508 incident PD cases and used multivariable Cox proportional hazards models to estimate the risk of PD associated with each size fraction of PM independently.

Results: In models adjusted for age in months, smoking, region, population density, caffeine and ibuprofen intake, we observed no statistically significant associations between exposure to air pollution and PD risk. The relative risk (RR) comparing the top quartile to the bottom quartile of PM exposure was 1.03 (95\% Confidence Intervals (Cl): $0.78,1.37)$ for $\mathrm{PM}_{10}(\leq 10$ microns in diameter), 1.10 (95\% Cl: $0.83,1.45)$ for $\mathrm{PM}_{2.5}$ ( $\leq 2.5$ microns in diameter), and 0.93 (95\% Cl: $0.69,1.26)$ for $\mathrm{PM}_{10-2.5}$ (2.5 to 10 microns in diameter).

Conclusions: In this study, we found no evidence that exposure to air pollution is a risk factor for PD.

Keywords: Epidemiology, Cohort studies, Incidence studies, Parkinson disease/Parkinsonism

\section{Background}

Chronic exposure to air pollution has detrimental effects on human health [1-3]. However, little is known about the effects of air pollution on neurological outcomes and risk of Parkinson's disease (PD). The existence of a link between air pollution and PD risk is suggested by the observations that toxins in air pollution evoke a systemic inflammatory response and oxidative stress [4], markers of which have been shown in some studies to be elevated among PD patients [5]. The brain is particularly vulnerable to oxidative stress, due it's high consumption of oxygen, low level of antioxidants, high levels of polyunsaturated

\footnotetext{
* Correspondence: palacios@hsph.harvard.edu

'Department of Nutrition, Harvard School of Public Health, Boston,

Massachusetts, USA

${ }^{2}$ Channing Division of Network Medicine, Department of Medicine, Brigham and Women's Hospital and Harvard Medical School, Boston, Massachusetts, USA Full list of author information is available at the end of the article
}

fatty acids and elevated iron content (particularly in the substantia nigra, a key brain area for PD) [6]. Further, increased plasma levels of inflammatory markers have been associated in some studies $[7,8]$, whereas higher urate, a potent antioxidant, appears to have neuroprotective effects in experimental models $[9,10]$ and is associated with lower PD risk [11-13]. In a recent analysis, Willis et al. linked Environmental Protection Agency (EPA) data on lead, copper and mercury emissions with the Medicare dataset on the county level throughout the US, and showed increased risk of PD among participants living in urban counties with the highest reported emissions of copper and manganese [14]. An adverse effect of air pollution would be consistent with evidence that in some cases PD may originate in the olfactory bulb and may thus be caused by a pathogen that enters the body through the nasal pathway $[15,16]$. We thus examined in a large prospective study of US nurses, 
whether exposure to ambient $\mathrm{PM}_{10}, \mathrm{PM}_{2.5}$ and $\mathrm{PM}_{10-2.5}$ is associated with increased risk of PD.

\section{Methods}

We examined the effects on PD risk of exposure to particulate matter less than or equal to 10 microns $\left(\mathrm{PM}_{10}\right)$, less than or equal to 2.5 microns $\left(\mathrm{PM}_{2.5}\right)$, and between 2.5 and 10 microns in diameter $\left(\mathrm{PM}_{10-2.5}\right)$ in a large prospective cohort of older women with biennially updated addresses living throughout the contiguous United States. This study was approved by the Brigham and Women's Hospital IRB.

\section{Study population}

Since 1976, 121,700 female registered nurses have been participating in the Nurses' Health Study (NHS). The participants were recruited from 11 states (California, Connecticut, Florida, Maryland, Massachusetts, Michigan, New York, New Jersey, Pennsylvania, Ohio and Texas) and were between 30 and 55 years old at baseline. At baseline and every two years thereafter, participants received, at their residential address, questionnaires asking about lifestyle factors and health outcomes. A question regarding PD was first asked in 1994. The follow-up rate in the NHS has been above $90 \%$ for each follow-up cycle. Detailed description of the study cohort is provided elsewhere [17]. The Institutional Review Board (IRB) at the Brigham and Women's Hospital approved this study.

\section{Exposure assessment}

Monthly exposures to ambient air pollution were estimated for each participant using spatio-temporal models, discussed in detail elsewhere [18-20]. In brief, generalized additive models of $\mathrm{PM}_{10}$ from 1988 through 2007 were developed [19] for the continental United States (US), using monthly average $\mathrm{PM}_{10}$ data from EPA's Air Quality System (AQS), a nationwide network of continuous and filterbased monitors, as well as data from various other sources, including the Interagency Monitoring of Protected Visual Environments (IMPROVE) network, and several Harvardbased research studies. A geographic information system (GIS) was used to derive the following model covariates: population density, distance to nearest road, elevation, and urban land use. The estimation of $\mathrm{PM}_{2.5}$ was similar; however, because EPA AQS monitoring data for $\mathrm{PM}_{2.5}$ was not available prior to 1999 , separate models were created for pre- and post-1999 $\mathrm{PM}_{2.5}$. To estimate $\mathrm{PM}_{2.5}$ prior to 1999, the model relied on measured $\mathrm{PM}_{10}$ pre-1999 and the $\mathrm{PM}_{2.5}$ to $\mathrm{PM}_{10}$ ratio from the spatio-temporal model post-1999, as well as estimated extinction coefficients from airport visibility data. $\mathrm{PM}_{10-2.5}$ was estimated by subtracting values for $\mathrm{PM}_{2.5}$ from those for $\mathrm{PM}_{10}$. All models showed little bias and a high degree of precision when evaluated with a cross-validation approach, where a sub- section of the monitors were held out to compare predicted and observed values $[19,20]$.

\section{PD Ascertainment}

The method used to ascertain PD cases has been described previously [21]. Briefly, since 1994, new cases of $\mathrm{PD}$ in the NHS have been identified through biennial questionnaires. When a participant reports PD, consent is sought from the participant to contact their treating neurologist (or internist if the neurologist is not available) and upon receipt of the consent the doctor is contacted to complete a questionnaire to confirm the diagnosis of PD and send a copy of the medical records. Of the self-reported PD cases in the NHS, we were able to contact $86 \%$ and of those, $69 \%$ provided consent to review medical records (17\% did not give permission and $14 \%$ denied the diagnosis of PD). The medical records are reviewed by a movement disorder specialist (M.A.S.) blinded to the exposure status. A case is considered confirmed if the treating physician reported it as either definite or probable, or if the medical record included evidence of either a final diagnosis of PD made by a neurologist or evidence of two or more of the three cardinal signs of PD (bradykinesia, rigidity, rest tremor) in the absence of characteristics suggesting an alternate diagnosis. The main analyses were performed among confirmed cases. We performed sensitivity analyses including participants who reported PD but did not give consent to review their medical records. Of the 508 incident PD cases included in this study, 212 were definite and 296 were probable cases.

\section{Statistical analysis}

Cox proportional hazards models with age as the time scale were used to model the association between exposure to $\mathrm{PM}_{10}, \mathrm{PM}_{2.5}, \mathrm{PM}_{10-2.5}$, and PD. Person-months of follow-up were calculated from baseline (June 30, 1990, to allow for a 2-year lag prior to the first incident PD cases reported in this study) through the end of follow-up (June 30, 2008), death or date of PD diagnosis, whichever occurred earlier. Exposure to air pollution was included in the models as a time-dependent variable that was incremented each month. We focused on the cumulative average exposure to $\mathrm{PM}_{10}, \mathrm{PM}_{2.5}$ and $\mathrm{PM}_{10-2.5}$ up to 2 years before PD diagnosis to best capture any effects of air pollution before the onset of PD. In separate models, we also considered a lag of 5 years prior to diagnosis, as well as using PM exposure in 2000, when the PM data is most complete (results not shown). Analyses were adjusted for age in months, region of the United States (northeast,/midwest/west/south), pack years smoking, smoking status (never/past/current), population density, caffeine consumption and use of ibuprofen. Regarding ibuprofen use, our questionnaire asked the following 
question: "On average, how many days each month do you take the following medicine (ibuprofen)", and the responses were never, $1-4$ days, 5-14 days, 15-21 days, and 22 or more days. Participants taking the drug 1 or more days per month were considered ever users for the purpose of this study. We also conducted additional analyses adjusting for tract-level income and housing value, as taken from the 2000 US census [22]. These were included in models as time-dependent variables. Because dietary, lifestyle and geographic factors may modify the relationship between air pollution and PD, we conducted additional analyses, stratified by smoking, caffeine intake and ibuprofen use, the main known factors related to PD risk, as well as region of the US (as the pollutant type and thus the effect on PD may differ by region). For tests of trend, the median value in each quintile was used as a continuous variable to allow for nonlinear associations. SAS version 9.1 (SAS Institute, Cary, NC, USA) was used for the statistical analyses.

\section{Results}

Table 1 shows the baseline characteristics of the study population. There were 115,620 participants in the study at baseline, and 508 incident PD cases included in prospective analyses. The characteristics of the PD cases included in the study were as follows: the mean age at PD onset was 71 years, $30 \%$ were current smokers at baseline, $28 \%$ were ever users of ibuprofen (using one or more times per month), and the mean baseline caffeine among intake was $231 \mathrm{mg} /$ day. The average follow-up for participants included in the analyses was 16.6 years (SD: 3.5 years). All three measures of air pollution were positively associated with population density. $\mathrm{PM}_{10}$ was highly correlated with both $\mathrm{PM}_{2.5}$ and $\mathrm{PM}_{10-2.5}(\mathrm{r}=0.73$

Table 1 Age-standardized characteristics of the 111,769 study participants at baseline in 1990 with respect to categories of $\mathrm{PM}_{10}$

\begin{tabular}{|c|c|c|c|c|}
\hline \multirow[b]{2}{*}{ Pollution category } & \multicolumn{4}{|c|}{$\mathrm{PM}_{10}$} \\
\hline & Q1* & Q2 & Q3 & Q4 \\
\hline Median $\mathrm{PM}^{\mathrm{a}}$ & 19.0 & 22.6 & 26.0 & 31.8 \\
\hline Age, mean (sd) & $58.2(7.2)$ & $58.2(7.2)$ & $58.1(7.2)$ & $58.2(7.2)$ \\
\hline Never Smoker (\%) & 48.0 & 46.5 & 45.9 & 42.3 \\
\hline Pack years, mean (sd) & $12.8(19.3)$ & $13.1(19.4)$ & $13.0(19.1)$ & $13.9(19.5)$ \\
\hline Caffeine mg/day, mean (sd) & 284.2 & & & \\
\hline$(239.5)$ & 284.6 & & & \\
\hline$(238.1)$ & 280.2 & & & \\
\hline$(234.1)$ & 274.8 & & & \\
\hline \multicolumn{5}{|l|}{$(228.2)$} \\
\hline Ibuprofen ever user (\%) & 28.7 & 28.4 & 28.7 & 26.8 \\
\hline Census tract income ${ }^{\mathrm{b}}$, USD, mean (sd) & 51602.9 & & & \\
\hline (16926) & 58044.3 & & & \\
\hline$(22510.2)$ & 66772.3 & & & \\
\hline$(26322.7)$ & $66,772.3$ & & & \\
\hline \multicolumn{5}{|l|}{$(26322.7)$} \\
\hline$(\text { Population density })^{b}$, (persons/tract), mean, (sd) & 1436.3 & & & \\
\hline (2184.5) & 2139.3 & & & \\
\hline (3216.8) & 1922.6 & & & \\
\hline (3088.5) & 4449.4 & & & \\
\hline \multicolumn{5}{|l|}{$(9575.1)$} \\
\hline \multicolumn{5}{|l|}{ Region of US } \\
\hline 'Northeast Region & 12.2 & 18.5 & 41.8 & 61.2 \\
\hline 'Midwest region', \% & 31.8 & 26.2 & 27.2 & 14.7 \\
\hline 'West region', \% & 7.0 & 3.5 & 6.7 & 15.9 \\
\hline 'South region', \% & 49.0 & 51.8 & 24.3 & 8.2 \\
\hline
\end{tabular}

${ }^{*} \mathrm{Q}(1,2,3,4)$ - quartiles - categories $(\mathrm{C} 1, \mathrm{C} 2, \mathrm{C} 3$ and $\mathrm{C} 4)$ for distance to road as shown in Table 3. g/day: grams/day.

${ }^{\mathrm{a}} \mu \mathrm{g} / \mathrm{m}^{3}$ (PM).

${ }^{b}$ tract-level variable based on the 2000 US Census. 
and 0.82); however, $\mathrm{PM}_{2.5}$ and $\mathrm{PM}_{10-2.5}$ were not highly correlated $(r=0.26)$.

We found no statistically significant associations between air pollution and PD risk. The relative risk (RR) comparing the top quartile to the bottom quartile of PM exposure was 1.03 (95\% Confidence Intervals (CI): 0.78, 1.37) for $\mathrm{PM}_{10}$ ( $\leq 10$ microns in diameter), 1.10 (95\% CI: $0.83,1.45)$ for $\mathrm{PM}_{2.5}$ ( $\leq 2.5$ microns in diameter), and 0.93 (95\% CI: $0.69,1.26)$ for $\mathrm{PM}_{10-2.5}(2.5$ to 10 microns in diameter). These results are shown in Table 2.

In stratified analyses, we did not observe any statistically significant interactions with smoking caffeine consumption and PM exposure (Table 3). The effect of PM on PD risk did not differ significantly by region of the US.

Our analyses did not differ notably with additional adjustment for tract-level income and housing value. Analyses using pollution values in 2000 as the exposure and lagging PM exposure by 5 years with respect to PD onset also did not differ materially from the primary analyses. Analyses that also included cases that did not confirm their diagnosis of PD cases were similar to the main analyses. We conducted additional sensitivity analyses among non-movers (Table 4), the results of which were not significantly different from those of our main analyses.

\section{Discussion}

In this study, we did not observe a statistically significant increase in PD risk associated with exposure to ambient air pollution measured as cumulative exposure to $\mathrm{PM}_{2.5}$, $\mathrm{PM}_{10}$ and $\mathrm{PM}_{10-2.5}$ at the residential address. We did not observe any interaction with smoking or caffeine for any of the size fractions. An interaction was observed between $\mathrm{PM}_{10}$ and $\mathrm{PM}_{10-2.5}$ and use of ibuprofen, but this this was an unexpected finding and could have occurred by chance.

$\mathrm{PM}_{10}$ includes all particles smaller than 10 microns in diameter; a size considered to be small enough to pass through the throat or the nose and enter the lungs, thus potentially causing harm to human health. $\mathrm{PM}_{10}$ includes inhalable coarse particles $\left(\mathrm{PM}_{10-2.5}\right)$ and fine particles $\left(\mathrm{PM}_{2.5}\right)$. Inhalable coarse particles, $\mathrm{PM}_{10-2.5}$ comes primarily from agricultural, mining and construction sources [23]. Fine particles, $\mathrm{PM}_{2.5}$, consists primarily of combustion particles from the burning of coal, wood and fuel oil and from motor vehicle emissions [23]. Exposure to PM has been associated with many harmful effects on human health. The Harvard Six Cities Study [1] and the American Cancer Society Study [2] were the first major studies to link exposure to air pollution to all cause mortality (The RR for all cause mortality in the

Table 2 Exposure to $\mathrm{PM}_{10}, \mathrm{PM}_{2.5}$, and $\mathrm{PM}_{10-2.5}$ and risk of PD in the Nurses' Health Study, 1990-2008 (N = 111,769 women at baseline)

\begin{tabular}{|c|c|c|c|c|c|c|c|}
\hline & \multirow[b]{2}{*}{ PY } & \multirow[b]{2}{*}{ Cases } & \multicolumn{2}{|c|}{ Age adjusted } & \multicolumn{3}{|c|}{ Multivariate $^{\mathrm{a}}$} \\
\hline & & & RR & $95 \% \mathrm{Cl}$ & RR & $95 \% \mathrm{Cl}$ & P-trend \\
\hline \multicolumn{8}{|l|}{ Quartiles of $\mathrm{PM}_{10}$} \\
\hline $3.8-21.0 \mu \mathrm{g} / \mathrm{m}^{3}$ & 484444 & 141 & 1.00 & Ref & 1.00 & Ref & \\
\hline $21.0-24.3 \mu \mathrm{g} / \mathrm{m}^{3}$ & 484483 & 135 & 1.06 & $(0.83,1.34)$ & 1.09 & $(0.86,1.39)$ & \\
\hline $24.3-28.3 \mu \mathrm{g} / \mathrm{m}^{3}$ & 484520 & 120 & 1.02 & $(0.80,1.30)$ & 1.03 & $(0.80,1.32)$ & \\
\hline $28.3-88.3 \mu \mathrm{g} / \mathrm{m}^{3}$ & 484550 & 112 & 1.03 & $(0.80,1.32)$ & 1.03 & $(0.78,1.37)$ & 0.92 \\
\hline Continuous^ $\mathrm{PM}_{10}$ & 1937996 & 508 & 0.99 & $(0.86,1.12)$ & 0.99 & $(0.84,1.16)$ & \\
\hline \multicolumn{8}{|l|}{ Quartiles of $\mathrm{PM}_{2.5}$} \\
\hline $1.2-12.6 \mu \mathrm{g} / \mathrm{m}^{3}$ & 484429 & 131 & 1.00 & Ref & 1.00 & Ref & \\
\hline $12.6-15.0 \mu \mathrm{g} / \mathrm{m}^{3}$ & 484482 & 131 & 1.12 & $(0.88,1.43)$ & 1.07 & $(0.83,1.38)$ & \\
\hline $15.0-17.4 \mu \mathrm{g} / \mathrm{m}^{3}$ & 484513 & 137 & 1.23 & $(0.97,1.57)$ & 1.14 & $(0.88,1.48)$ & \\
\hline $17.4-73.9 \mu \mathrm{g} / \mathrm{m}^{3}$ & 484573 & 109 & 1.17 & $(0.90,1.51)$ & 1.10 & $(0.83,1.45)$ & 0.43 \\
\hline Continuous^ $\mathrm{PM}_{2.5}$ & 1937996 & 508 & 1.17 & $(0.90-1.51)$ & 1.08 & $(0.81-1.45)$ & \\
\hline \multicolumn{8}{|l|}{ Quartiles of $\mathrm{PM}_{10-2.5}$} \\
\hline $0-7.2 \mu \mathrm{g} / \mathrm{m}^{3}$ & 484479 & 149 & 1.00 & (Ref) & 1.00 & (Ref) & \\
\hline $7.2-9.2 \mu \mathrm{g} / \mathrm{m}^{3}$ & 484496 & 121 & 0.87 & $(0.69,1.11)$ & 0.91 & $(0.71,1.16)$ & \\
\hline $9.2-12.0 \mu \mathrm{g} / \mathrm{m}^{3}$ & 484495 & 119 & 0.87 & $(0.68,1.11)$ & 0.93 & $(0.72,1.20)$ & \\
\hline $12.0-67.1 \mathrm{\mu g} / \mathrm{m}^{3}$ & 484506 & 119 & 0.87 & $(0.68,1.11)$ & 0.93 & $(0.69,1.26)$ & 0.64 \\
\hline Continuous^ $\mathrm{PM}_{10-25}$ & 1937996 & 508 & 0.90 & $(0.74-1.09)$ & 0.92 & $(0.71-1.19)$ & \\
\hline
\end{tabular}

$P Y$ : person years; $R R$ : relative risk; $95 \% \mathrm{Cl}$ : 95 percent confidence interval.

adjusted for age, smoking, region (northeast, midwest, west, and south), population density, caffeine intake (<100 mg/day vs. over $100 \mathrm{mg} / \mathrm{day})$ and ibuprofen use (ever/never user).

$\wedge$ per $10 \mu \mathrm{g} / \mathrm{m}^{3}$. 
Table 3 Exposure to PM and risk of PD in the Nurses' Health Study, 1990-2008 $(\mathrm{N}=111,769)$ by smoking status, caffeine intake and ibuprofen use

\begin{tabular}{|c|c|c|c|c|c|c|c|c|c|}
\hline \multirow[b]{2}{*}{ By smoking status: } & PY & Cases & $\mathrm{RR}^{\mathrm{a}}$ & $95 \% \mathrm{Cl}$ & PY & Cases & $\mathrm{RR}^{\mathrm{a}}$ & $95 \% \mathrm{Cl}$ & p-int \\
\hline & \multicolumn{4}{|c|}{ Never smokers } & \multicolumn{5}{|c|}{ Ever smokers } \\
\hline \multicolumn{10}{|l|}{ Quartiles of $\mathrm{PM}_{10}$} \\
\hline Q1 & 206697 & 73 & 1.00 & Ref & 278761 & 68 & 1.00 & Ref & \\
\hline Q2 & 209774 & 75 & 1.14 & $(0.82,1.58)$ & 275654 & 60 & 1.03 & $(0.72,1.47)$ & \\
\hline Q3 & 213834 & 63 & 0.99 & $(0.70,1.41)$ & 271618 & 57 & 1.05 & $(0.73,1.52)$ & \\
\hline Q4 & 213834 & 56 & 0.92 & $(0.62,1.36)$ & 265933 & 56 & 1.14 & $(0.76,1.71)$ & 0.31 \\
\hline Continuous* $\mathrm{PM}_{10}$ & 849835 & 267 & 0.96 & $(0.85,1.09)$ & 1091965 & 241 & 1.04 & $(0.92,1.18)$ & 0.42 \\
\hline \multicolumn{10}{|l|}{ Quartiles of $\mathrm{PM}_{2.5}$} \\
\hline Q1 & 210817 & 69 & 1.00 & Ref & 274637 & 62 & 1.00 & Ref & \\
\hline Q2 & 204967 & 69 & 1.07 & $(0.76,1.52)$ & 280601 & 62 & 1.06 & $(0.74,1.54)$ & \\
\hline Q3 & 214387 & 70 & 1.07 & $(0.74,1.53)$ & 271003 & 67 & 1.21 & $(0.84,1.76)$ & \\
\hline Q4 & 219664 & 59 & 1.06 & $(0.72,1.55)$ & 265724 & 50 & 1.12 & $(0.74,1.69)$ & 0.58 \\
\hline Continuous* $\mathrm{PM}_{2.5}$ & 849835 & 267 & 1.01 & $(0.90,1.15)$ & 1091965 & 241 & 1.05 & $(0.92,1.19)$ & 0.66 \\
\hline \multicolumn{10}{|l|}{ Quartiles of $\mathrm{PM}_{10-2.5}$} \\
\hline Q1 & 212002 & 85 & 1.00 & Ref & 273461 & 64 & 1.00 & Ref & \\
\hline Q2 & 204860 & 60 & 0.79 & $(0.57,1.11)$ & 280562 & 61 & 1.05 & $(0.74,1.51)$ & \\
\hline Q3 & 210385 & 58 & 0.77 & $(0.54,1.09)$ & 274925 & 61 & 1.14 & $(0.79,1.65)$ & \\
\hline Q4 & 222580 & 64 & 0.82 & $(0.54,1.24)$ & 263007 & 55 & 1.05 & $(0.67,1.65)$ & 0.26 \\
\hline Continuous^ $\mathrm{PM}_{10-25}$ & 849835 & 267 & 0.93 & $(0.81,1.05)$ & 1091965 & 241 & 1.03 & $(0.90,1.18)$ & 0.41 \\
\hline By Caffeine intake: & \multicolumn{4}{|c|}{$<100 \mathrm{mg} /$ day caffeine } & \multicolumn{5}{|c|}{$>=100 \mathrm{mg} /$ day caffeine } \\
\hline \multicolumn{10}{|l|}{ Quartiles of $\mathrm{PM}_{10}$} \\
\hline Q1 & 196761 & 69 & 1.00 & Ref & 287683 & 72 & 1.00 & (Ref) & \\
\hline Q2 & 189470 & 69 & 1.20 & $(0.85,1.68)$ & 295013 & 66 & 0.99 & $(0.70,1.40)$ & \\
\hline Q3 & 189270 & 73 & 1.35 & $(0.95,1.91)$ & 295251 & 47 & 0.74 & $(0.50,1.08)$ & \\
\hline Q4 & 184296 & 57 & 1.20 & $(0.81,1.78)$ & 300254 & 55 & 0.87 & $(0.60,1.31)$ & 0.23 \\
\hline Continuous* $\mathrm{PM}_{10}$ & 759796 & 268 & 1.08 & $(0.95,1.22)$ & 1178200 & 240 & 0.93 & $(0.81,1.06)$ & 0.49 \\
\hline \multicolumn{10}{|l|}{ Quartiles of $\mathrm{PM}_{2.5}$} \\
\hline Q1 & 194876 & 65 & & (Ref) & 289553 & 66 & 1.00 & (Ref) & \\
\hline Q2 & 189312 & 68 & 1.02 & $(0.71,1.46)$ & 295169 & 63 & 0.77 & $(0.53,1.10)$ & \\
\hline Q3 & 194935 & 74 & 1.06 & $(0.73,1.55)$ & 289578 & 63 & 0.86 & $(0.60,1.24)$ & \\
\hline Q4 & 180673 & 61 & 0.88 & $(0.58,1.32)$ & 303900 & 48 & 0.69 & $(0.44,1.09)$ & 0.22 \\
\hline Continuous* $\mathrm{PM}_{25}$ & 759796 & 268 & 0.97 & $(0.85,1.10)$ & 120299 & 240 & 0.91 & $(0.79,1.04)$ & 0.38 \\
\hline \multicolumn{10}{|l|}{ Quartiles of $\mathrm{PM}_{10-2.5}$} \\
\hline Q1 & 196694 & 76 & 1.00 & (Ref) & 287785 & 73 & 1.00 & (Ref) & \\
\hline Q2 & 185789 & 67 & 1.05 & $(0.75,1.47)$ & 298707 & 54 & 0.77 & $(0.53,1.10)$ & \\
\hline Q3 & 188793 & 59 & 0.99 & $(0.70,1.43)$ & 295702 & 60 & 0.86 & $(0.60,1,24)$ & \\
\hline Q4 & 188513 & 66 & 1.20 & $(0.79,1.80)$ & 295993 & 53 & 0.69 & $(0.44,1.09)$ & 0.45 \\
\hline Continuous^ $\mathrm{PM}_{10-25}$ & 759796 & 268 & 1.04 & $(0.92,1.19)$ & 1178200 & 240 & 0.91 & $(0.79,1.04)$ & 0.72 \\
\hline By use of ibuprofen & Never u & & & & Ever use & & & & \\
\hline \multicolumn{10}{|l|}{ Quartiles of $\mathrm{PM}_{10}$} \\
\hline Q1 & 378733 & 101 & 1.00 & (Ref) & 105711 & 40 & 1.00 & (Ref) & \\
\hline Q2 & 375957 & 110 & 1.22 & $(0.93,1.61)$ & 108526 & 25 & 0.76 & $(0.45,1.26)$ & \\
\hline Q3 & 373161 & 87 & 1.04 & $(0.77,1.40)$ & 111359 & 33 & 1.03 & $(0.63,1.68)$ & \\
\hline Q4 & 369737 & 95 & 1.20 & $(0.87,1.65)$ & 114813 & 17 & 0.62 & $(0.33,1.16)$ & 0.04 \\
\hline
\end{tabular}


Table 3 Exposure to PM and risk of PD in the Nurses' Health Study, 1990-2008 $(\mathrm{N}=111,769)$ by smoking status, caffeine intake and ibuprofen use (Continued)

\begin{tabular}{|c|c|c|c|c|c|c|c|c|c|}
\hline Continuous ${ }^{*} \mathrm{PM}_{10}$ & 1491149 & 375 & 1.04 & $(0.04,1.15)$ & 440409 & 115 & 0.91 & $(0.75,1.10)$ & 0.03 \\
\hline \multicolumn{10}{|l|}{ Quartiles of $\mathrm{PM}_{2.5}$} \\
\hline Q1 & 377642 & 101 & 1.00 & (Ref) & 106787 & 30 & 1.00 & (Ref) & \\
\hline Q2 & 376538 & 103 & 1.16 & $(0.87,1.55)$ & 107943 & 28 & 0.81 & $(0.47,1.37)$ & \\
\hline Q3 & 375892 & 98 & 1.13 & $(0.84,1.52)$ & 108622 & 39 & 1.14 & $(0.68,1.91)$ & \\
\hline Q4 & 367516 & 91 & 1.26 & $(0.87,1.55)$ & 117056 & 18 & 0.64 & $(0.34,1.20)$ & 0.43 \\
\hline Continuous* $\mathrm{PM}_{25}$ & 1491149 & 393 & 1.07 & $(0.97,1.18)$ & 440409 & 115 & 0.93 & $(0.77,1.12)$ & 0.38 \\
\hline \multicolumn{10}{|l|}{ Quartiles of $\mathrm{PM}_{10-2.5}$} \\
\hline Q1 & 375666 & 107 & 1.00 & Ref & 108813 & 42 & 1.00 & (Ref) & \\
\hline Q2 & 374592 & 90 & 0.92 & $(0.70,1.23)$ & 109905 & 31 & 0.81 & $(0.50,1.30)$ & \\
\hline Q3 & 375149 & 98 & 1.02 & $(0.77,1.35)$ & 109346 & 21 & 0.56 & $(0.33,0.96)$ & \\
\hline Q4 & 372167 & 98 & 1.01 & $(0.76,1.36)$ & 112339 & 21 & 0.55 & $(0.32,0.97)$ & 0.01 \\
\hline Continuous^ $\mathrm{PM}_{10-25}$ & 1497588 & 393 & 1.01 & $(0.92,1.11)$ & 440409 & 115 & 0.80 & $(0.67,0.96)$ & 0.01 \\
\hline
\end{tabular}

Abbreviations: $P Y$ person years; $R R$ relative risk; $95 \%$ Cl 95 percent confidence interval.

adjusted for age, smoking (except in smoking stratified analyses), region (northeast, midwest, west, and south), population density, caffeine intake (<100 mg/day vs. over $100 \mathrm{mg} /$ day, except in caffeine stratified analyses) and ibuprofen use (ever/never user, except in ibuprofen stratified analyses). $\wedge$ per $10 \mu \mathrm{g} / \mathrm{m}^{3}$.

Table 4 Exposure to $\mathrm{PM}_{10}, \mathrm{PM}_{2.5}$, and $\mathrm{PM}_{10-2.5}$ and risk of PD in the Nurses' Health Study among non-movers, 1990-2008 ( $N=80,544$ women at baseline who did not move during the study)

\begin{tabular}{|c|c|c|c|c|c|}
\hline & \multicolumn{5}{|c|}{ Multivariate $^{a}$} \\
\hline & PY & Cases & $\mathbf{R R}$ & $95 \% \mathrm{Cl}$ & P-trend \\
\hline \multicolumn{6}{|l|}{ Quartiles of $\mathrm{PM}_{10}$} \\
\hline $3.8-21.0 \mu \mathrm{g} / \mathrm{m}^{3}$ & 395353 & 123 & 1.00 & Ref & \\
\hline $21.0-24.3 \mu \mathrm{g} / \mathrm{m}^{3}$ & 395383 & 115 & 1.09 & $(0.84,1.41)$ & \\
\hline $24.3-28.3 \mu \mathrm{g} / \mathrm{m}^{3}$ & 395419 & 100 & 1.00 & $(0.76,1.33)$ & \\
\hline $28.3-88.3 \mu \mathrm{g} / \mathrm{m}^{3}$ & 395426 & 90 & 0.98 & $(0.76,1.33)$ & 0.92 \\
\hline Continuous^ $\mathrm{PM}_{10}$ & 1581580 & 430 & 0.99 & $(0.89,1.09)$ & \\
\hline \multicolumn{6}{|l|}{ Quartiles of $\mathrm{PM}_{2.5}$} \\
\hline $1.2-12.6 \mu \mathrm{g} / \mathrm{m}^{3}$ & 395343 & 110 & 1.00 & Ref & \\
\hline $12.6-15.0 \mu \mathrm{g} / \mathrm{m}^{3}$ & 395383 & 111 & 1.10 & $(0.83,1.45)$ & \\
\hline $15.0-17.4 \mu \mathrm{g} / \mathrm{m}^{3}$ & 395409 & 121 & 1.25 & $(0.94,1.65)$ & \\
\hline $17.4-73.9 \mu \mathrm{g} / \mathrm{m}^{3}$ & 395446 & 88 & 1.11 & $(0.81,1.52)$ & 0.43 \\
\hline Continuous^ $\mathrm{PM}_{2.5}$ & 158446 & 430 & 1.08 & $(0.81-1.45)$ & \\
\hline \multicolumn{6}{|l|}{ Quartiles of $\mathrm{PM}_{10-2.5}$} \\
\hline $0-7.2 \mu \mathrm{g} / \mathrm{m}^{3}$ & 395375 & 132 & 1.00 & $(\operatorname{Ref})$ & \\
\hline $7.2-9.2 \mu \mathrm{g} / \mathrm{m}^{3}$ & 395394 & 106 & 0.93 & $(0.71,1.21)$ & \\
\hline $9.2-12.0 \mu \mathrm{g} / \mathrm{m}^{3}$ & 395397 & 96 & 0.90 & $(0.68,1.20)$ & \\
\hline $12.0-67.1 \mu \mathrm{g} / \mathrm{m}^{3}$ & 395395 & 96 & 0.90 & $(0.63,1.28)$ & 0.64 \\
\hline Continuous^ $\mathrm{PM}_{10-25}$ & 1937996 & 430 & 0.95 & $(0.85-1.05)$ & \\
\hline
\end{tabular}

PY: person years; $R R$ : relative risk; $95 \%$ Cl: 95 percent confidence interval. adjusted for age, smoking, region (northeast, midwest, west, and south), population density, caffeine intake ( $<100 \mathrm{mg} /$ day vs. over $100 \mathrm{mg} /$ day) and ibuprofen use (ever/never user).

$\wedge$ per $10 \mu \mathrm{g} / \mathrm{m}^{3}$. extended follow-up of the Harvard Six Cities Study was 1.16 (95\% CI: 1.07-1.26) [24]). Since then, many more studies have documented the detrimental effects of chronic exposure to air pollution on human health and survival $[24,25]$.

Prior work on air pollution and PD has been limited. Finkelstein and colleagues [26], found that although markers of traffic derived air pollution did not predict PD risk, risk was increased among participants with higher Manganese (Mn) exposure (RR: 1.03; 95\% CI: 1.00-1.07) for each $10 \mathrm{ng} / \mathrm{m}^{3}$ increase in Mn concentration) [26]. In a recent study that used GIS to link airborne metal exposure data throughout the US to the Medicare beneficiaries database, Willis and colleagues found a higher incidence of PD in urban counties with higher industrial release of copper and manganese [14]. Also, a number of studies have linked occupational manganese exposure to risk of Parkinsonian syndromes [27,28] although this is thought to be distinct from PD [29].

Our study's estimates of PM air pollution have an advantage over what was done in prior studies because the measures are based on a comprehensive prediction model of PM. This model allows us to estimate air pollution levels for an entire cohort of non-occupationally exposed participants at each participant's residential address. Also, our air pollution models used GIS-based spatio-temporal statistics with GIS covariates that allow us to account for small-scale variations in pollution around each woman's address and to estimate the pollution level for each address that each study participant has reported during the study period, thus giving us a 
more accurate measure of exposure to air pollution over time than past studies.

Animal studies suggest that PM may access the brain either through the nasal pathway or through the circulation $[15,16,23,30]$. Fine particles in the central nervous system have been associated with increased brain inflammation in several studies [31-33]. In one study, levels of several pro-inflammatory cytokines were elevated in the brains of mice exposed to high levels of particulate matter compared to controls [31]. In another study in rats, exposure to diesel exhaust was associated with an increase of a number of inflammatory factors, including whole-brain IL-6 and TNF $\alpha$, among others [34]. Furthermore, a study of Mexico city residents, showed higher levels of neuroinflammation of the olfactory bulb (as indicated by higher levels of COX 2 and IL1 $\beta$ ) and higher concentrations of metals associated with PM (including manganese, nickel and chromium) among inhabitants of urban areas [35]. A study using autopsies of brains from children and young adults in Mexico City, Mexico found elevation of indices on neuroinflammation and oxidative stress in the brains of participants exposed to high levels of particulate matter [36]. Higher levels of inflammatory factors in the brain have been linked with increased risk of PD in several studies. PD patients had significantly higher levels of oxidized -LDL and highsensitivity of C-reactive protein (both markers of inflammation) compared to controls in one study [5,7], and elevated levels of Il-6, but not CRP in another study [7].

Measurement of long-term exposure to air pollution is prone to substantial error, which under most circumstances would tend to attenuate an association with PD risk. In this study, we only had information on air pollution exposure from 1988 onwards, due to the availability of the modeled air pollution data. This period covers only adulthood exposure for our study population. It is conceivable, although this has not been determined, that the relevant etiological period may include exposure during childhood or, more generally, for a longer period of time than we were able to capture in this study. To address this issue, we conducted a sensitivity analysis restricted to women who did not move during the study (with the presumption that those women were also more likely to maintain a single residence prior to study baseline) (Table 4). In analyses restricted to women who maintained the same State and County (430 PD cases) and in analyzes among women who maintained the same latitude and longitude (291 PD cases) throughout the study, our results still did not indicate a significant association between exposure to PM air pollution and risk of PD (results not shown). Furthermore, because direct measurement data on $\mathrm{PM}_{2.5}$ was only available post-1999, we conducted sensitivity analyses starting follow-up in 1999 and only using the 311 PD cases onset after January 11999.
The results of these analyses did not differ significantly from our main results.

Another limitation of our study is in the exposure assessment: we did not have personal air pollution measurements in this study or indoor air pollution measures and we do not know how much time people spend indoors vs. outdoors at their address. Due to the large scale of this study, it was only possible to use indirect measures of air pollution, collected via GIS-based modeling of pollution based on values measured by monitors throughout the US. Although the models used to estimate PM in the NHS have been shown to have little bias and high precision, [37,38] especially when compared with other methods of estimating air pollution [18,19], some misclassification of the biologically relevant levels of individual exposure is inevitable and could have attenuated the association between air pollution and PD risk. Finally, as in most epidemiological studies of a rare disease such as PD, power and sample size restrict our ability to detect associations - in this study we had $80 \%$ power to detect relative risks of 1.45 or above, comparing the highest quartile of pollution to the lowest quartile, assuming a 2-sided test with an alpha of 0.05. We expect that associations below this threshold would have been seen as suggestive, although not statistically significant findings. Also, there is also potential for occupational exposure to air pollution with the nursing occupation, which we were unable to account for in this study. Finally, we only had information on residential address, and were not able to account for exposure to ambient air pollution during the time that our study participants spent at work.

The strengths of this study include its' large size, a long and prospective follow-up, a high response rate and the availability of $\mathrm{PM}_{10}, \mathrm{PM}_{2.5}, \mathrm{PM}_{10-2.5}$ estimates at each woman's residential address on a monthly basis throughout the study. The pollution data was available throughout the continental US, allowing for sufficient variability to detect a potential contrast in the analytical categories as well as representativeness of the pollution levels to which residents of the US are commonly exposed.

\section{Conclusion}

In summary, overall the results of this large cohort study of female nurses do not support an effect of air pollution on PD risk.

\section{Abbreviations}

AQS: Air quality system; Cl: Confidence intervals; EPA: Environmental Protection Agency; GIS: Geographic information system; IMPROVE: Interagency Monitoring of Protected Visual Environments; IRB: Institutional Review Board; Mn: Manganese; NHS: Nurses' Health Study; PD: Parkinson's disease; PM: Particulate matter; RR: Relative risk; US: United States. 


\section{Competing interests}

Dr. Palacios reports no disclosures. Dr. Hart reports no disclosures. Ms. Fitzgerald reports no disclosures. Dr. Weisskopf reports no disclosures. Dr. Schwarzschild has received funding from the Michael J. Fox Foundation, Parkinson Disease Foundation, the RJG Parkinson's Disease Foundation, and the Parkinson Disease Foundation program, Parkinson's Disease Foundation Parkinson's research program. Dr. Ascherio has received honoraria for speaking at scientific symposia by Roche, Sanofi Aventis, Serono, and Almirall and has received research funding from the ALS Therapy Alliance, the Michael J. Fox Foundation, and the National Institutes of Health. Dr. Laden reports no disclosures.

\section{Authors' contributions}

$N P$ is responsible for the design and conceptualization of the study, analysis and interpretation of the data, drafting and revising the manuscript. JEH was responsible for revising the manuscript. She provided expertise in the air pollution dataset. KF was responsible for statistical analysis and interpretation of the data. MW was involved in the design and conceptualization of the study and revising the manuscript. MAS was responsible for the interpretation of the data and revising the manuscript. AA was involved in the design and conceptualization of the study and revising the manuscript. FL was involved in the design and conceptualization of the study and revising the manuscript. She provided expertise in the air pollution dataset. All authors read and approved the final manuscript.

\section{Acknowledgements}

The authors would like to acknowledge Leslie Unger for administrative support and Dr. Eilis O'Reilly for statistical advice. Study Funding: Supported by NIH (K01ES019183).

\section{Author details}

'Department of Nutrition, Harvard School of Public Health, Boston, Massachusetts, USA. ${ }^{2}$ Channing Division of Network Medicine, Department of Medicine, Brigham and Women's Hospital and Harvard Medical School, Boston, Massachusetts, USA. ${ }^{3}$ Department of Neurology, Massachusetts General Hospital, Boston, Massachusetts, USA. ${ }^{4}$ Department of Environmental Health, Harvard School of Public Health, Boston, Massachusetts, USA. ${ }^{5}$ Department of Epidemiology, Harvard School of Public Health, Boston, Massachusetts, USA.

Received: 11 March 2014 Accepted: 12 September 2014 Published: 7 October 2014

\section{References}

1. Dockery DW, Pope CA, Xu X, Spengler JD, Ware JH, Fay ME, Ferris BG, Speizer FE: An Association between Air Pollution and Mortality in Six U.S. Cities. N Engl J Med 1993, 329:1753-1759.

2. Pope CA 3rd, Thun MJ, Namboodiri MM, Dockery DW, Evans JS, Speizer FE, Heath CW Jr: Particulate air pollution as a predictor of mortality in a prospective study of U.S. adults. Am J Respir Crit Care Med 1995, 151:669-674.

3. Lepeule J, Laden F, Dockery D, Schwartz J: Chronic Exposure to Fine Particles and Mortality: An Extended Follow-Up of the Harvard Six Cities Study from 1974 to 2009. Environ Health Perspect 2012, 120:965-970.

4. Seaton AMW, Donaldson K, Godden D: Particulate air pollution and acute health effects. Lancet 1995, 345:176-178.

5. Andican G, Konukoglu D, Bozluolcay M, Bayulkem K, Firtiina S, Burcak G: Plasma oxidative and inflammatory markers in patients with idiopathic Parkinson's disease. Acta Neurol Belg 2012, 112:155-159.

6. Chinta SJ, Andersen JK: Redox imbalance in Parkinson's disease. Biochim Biophys Acta Gen Subj 2008, 1780:1362-1367.

7. Chen H, O'Reilly E, Schwarzschild MA, Ascherio A: Peripheral inflammatory biomarkers and risk of Parkinson's disease. Am J Epidemiol 2008, 167:90-95.

8. Ton TG, Jain S, Biggs ML, Thacker EL, Strotmeyer ES, Boudreau R, Newman $A B$, Longstreth WT Jr, Checkoway H: Markers of inflammation in prevalent and incident Parkinson's disease in the Cardiovascular Health Study. Parkinsonism Relat Disord 2012, 18:274-278.

9. Haberman F, Tang SC, Arumugam TV, Hyun DH, Yu QS, Cutler RG, Guo Z, Holloway HW, Greig NH, Mattson MP: Soluble neuroprotective antioxidant uric acid analogs ameliorate ischemic brain injury in mice. Neuromolecular Med 2007, 9:315-323.
10. Wang LJLW, Wang $H H, N i G H, Y e Y$ : Protective effects of uric acid on nigrostriatal system injury induced by 6-hydroxydopamine in rats. Zhonghua Yi Xue Za Zhi 2010, 90:1362-1365.

11. Weisskopf MG, O'Reilly E, Chen H, Schwarzschild MA, Ascherio A: Plasma urate and risk of Parkinson's disease. Am J Epidemiol 2007, 166:561-567.

12. de Lau LM, Koudstaal PJ, Hofman A, Breteler MM: Serum uric acid levels and the risk of Parkinson disease. Ann Neurol 2005, 58:797-800.

13. Davis JW, Grandinetti A, Waslien Cl, Ross GW, White LR, Morens DM: Observations on serum uric acid and the risk of idiopathic Parkinson's disease. Am J Epidemiol 1996, 144:480-484.

14. Willis AW, Evanoff BA, Lian M, Galarza A, Wegrzyn A, Schootman M, Racette BA: Metal Emissions and Urban Incident Parkinson Disease: A Community Health Study of Medicare Beneficiaries by Using Geographic Information Systems. Am J Epidemiol 2010, 172(12):1357-1363.

15. Hawkes CH, Del Tredici K, Braak H: Parkinson's disease: the dual hit theory revisited. Ann N Y Acad Sci 2009, 1170:615-622.

16. Hawkes $\mathrm{CH}$, Del Tredici K, Braak H: Parkinson's disease: a dual-hit hypothesis. Neuropathol Appl Neurobiol 2007, 33:599-614.

17. Colditz GA, Manson JE, Hankinson SE: The Nurses' Health Study: 20-year contribution to the understanding of health among women. J Womens Health 1997, 6:49-62.

18. Puett RC, Schwartz J, Hart JE, Yanosky JD, Speizer FE, Suh H, Paciorek CJ, Neas LM, Laden F: Chronic Particulate Exposure, Mortality, and Coronary Heart Disease in the Nurses' Health Study. Am J Epidemiol 2008, 168:1161-1168.

19. Yanosky JD, Paciorek CJ, Schwartz J, Laden F, Puett R, Suh HH: Spatio-temporal modeling of chronic PM10 exposure for the Nurses' Health Study. Atmos Environ 2008, 42:4047-4062.

20. Wong KT, Grove JS, Grandinetti A, Curb JD, Yee M, Blanchette P, Ross GW, Rodriguez Bl: Association of Fibrinogen with Parkinson Disease in Elderly Japanese-American Men: A Prospective Study. Neuroepidemiology 2010, 34:50-54.

21. Ascherio A, Zhang SM, Hernán MA, Kawachi I, Colditz GA, Speizer FE, Willett WC: Prospective study of caffeine consumption and risk of Parkinson's disease in men and women. Ann Neurol 2001, 50:56-63.

22. US Census: US Census; 2000. [http://www.census.gov/main/www/cen2000. html]

23. PM. [http://www.epa.gov/pm/]

24. Laden F, Schwartz J, Speizer FE, Dockery DW: Reduction in Fine Particulate Air Pollution and Mortality. Am J Respir Crit Care Med 2006, 173:667-672.

25. Hart JE, Laden F, Puett RC, Costenbader KH, Karlson EW: Exposure to Traffic Pollution and Increased Risk of Rheumatoid Arthritis. Environ Health Perspect 2009, 117:1065-1069

26. Finkelstein MM, Jerrett $\mathrm{M}$ : A study of the relationships between Parkinson's disease and markers of traffic-derived and environmental manganese air pollution in two Canadian cities. Environ Res 2007, 104:420-432.

27. Guilarte TR: Manganese and Parkinson's disease: a critical review and new findings. Environ Health Perspect 2010, 118:1071-1080.

28. Bowler RM, Koller W, Schulz PE: Parkinsonism due to manganism in a welder: Neurological and neuropsychological sequelae. Neurotoxicology 2006, 27:327-332.

29. Jankovic J: Searching for a relationship between manganese and welding and Parkinson's disease. Neurology 2005, 64:2021-2028.

30. Hedström A, Hillert J, Olsson T, Alfredsson L: Nicotine might have a protective effect in the etiology of multiple sclerosis. Multiple Sclerosis J 2013, 19:1009-1013.

31. Campbell A, Oldham M, Becaria A, Bondy SC, Meacher D, Sioutas C, Misra C, Mendez LB, Kleinman M: Particulate Matter in Polluted Air May Increase Biomarkers of Inflammation in Mouse Brain. Neurotoxicology 2005, 26:133-140

32. Smith K, Kapoor R, Hall SM, Davies M: Electrically active axons degenerate when exposed to nitric oxide. Ann Neurol 2001, 49:470-476.

33. Bernatsky S, Fournier M, Pineau CA, Clarke AE, Vinet E, Smargiassi A: Associations between Ambient Fine Particulate Levels and Disease Activity in Patients with Systemic Lupus Erythematosus (SLE). Environ Health Perspect 2011, 119:45-49.

34. Levesque STT, Lull ME, Kodavanti U, Stadler K, Wagner A, Johnson JA, Duke L, Kodavanti P, Surace M, Block M: Diesel Exhaust Activates and Primes Microglia: Air Pollution Neuroinflammation, and Regulation of Dopaminergic Neurotoxicity. Environ Health Perspect 2011, 119:1149-1155. 
35. Calderon-Garciduanas LS-SA, Torres-Jardon R, Zhu H, Yuan Y, Smith D, Delgado-Chavez R, Cross JV, Medina-Cortina H, Kavanaugh M, Guilarte T: The impact of environmental metals in young urbanites brains. Exp Toxicol Pathol 2012, 65:503-511.

36. Calderon-Garciduanas LKM, Block M, D'Anguilli A, Delgado-Chavez R, Torres Jardon R, Gonzalez-Maciel A, Reynoso-Robies R, Osnaya N, Villarreal-Calderon R, Guo R, Hua Z, Zhu H, Perry G, Diaz P: Neuroinflammation, Hyperphosphorylated Tau, Diffuse Amyloid Plaques and Down-Regulation of the Cellular Prion Protein in Air Pollution Exposed Children and Young Adults. J Alzheimer's Disease 2012, 28:93-107.

37. Weuve J, Puett RC, Schwartz J, Yanosky JD, Laden F, Grodstein F: EXposure to particulate air pollution and cognitive decline in older women. Arch Intern Med 2012, 172:219-227.

38. Marrosu MG, Murru MR, Costa G, Cucca F, Sotgiu S, Rosati G, Muntoni F: Multiple sclerosis in Sardinia is associated and in linkage disequilibrium with HLA-DR3 and -DR4 alleles. Am J Hum Genet 1997, 61:454-457.

doi:10.1186/1476-069X-13-80

Cite this article as: Palacios et al.: Particulate matter and risk of

parkinson disease in a large prospective study of women. Environmental Health 2014 13:80.

\section{Submit your next manuscript to BioMed Central and take full advantage of:}

- Convenient online submission

- Thorough peer review

- No space constraints or color figure charges

- Immediate publication on acceptance

- Inclusion in PubMed, CAS, Scopus and Google Scholar

- Research which is freely available for redistribution 